\section{eduardo forroja}

$108-10$

FRANCO LEVI, presidente del C. E. B.

\title{
alma del comité europeo del hormigón
}

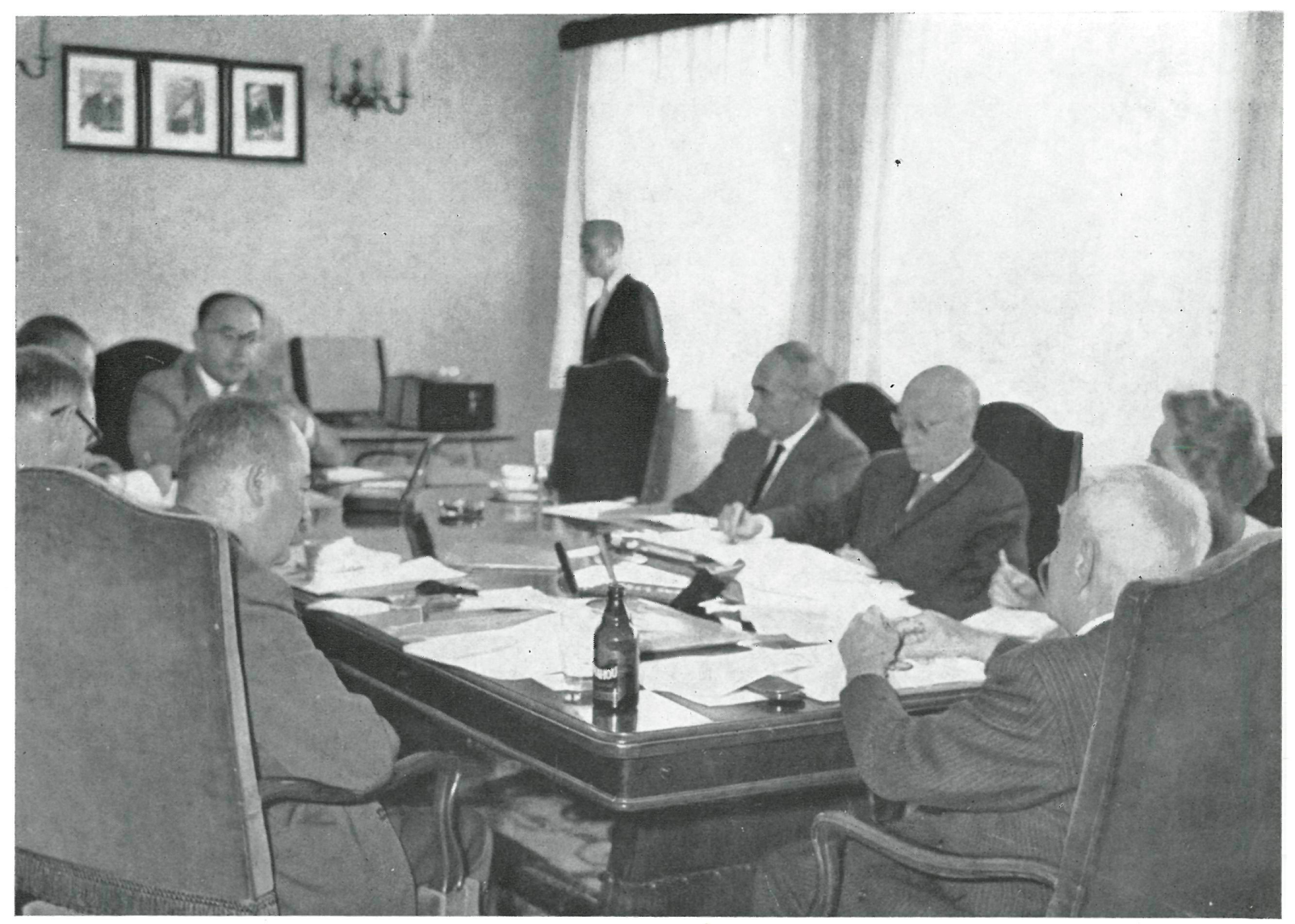

Es un hecho evidente que, durante los últimos años de su vida, Eduardo Torroja desarrolló una intensa actividad dedicando gran importancia al progreso de los trabajos del Comité Europeo del Hormigón. Este Comité, que es, en realidad, una Asociación de investigadores y constructores, y en cuya fundación participó en 1953, responde, efectivamente, a su aspiración más profunda: alcanzar un perfecto equilibrio, en todos los terrenos de la ingeniería, entre las exigencias de la técnica y las necesidades de la práctica. 
El autor de estas líneas, que se honra de haber gozado de la amistad particular de este gran hombre, posee en sus expedientes decenas y decenas de preciosos informes en los cuales Torroja reflejaba día tras día el fruto de su incansable trabajo, que abarcaba, prácticamente, todos los terrenos de la actividad del Comité. Durante las reuniones de índole técnica, su fecunda preparación se reflejaba en una aportación consiructiva, que prevalecía siempre por encima de las discusiones más encarnizadas o atacaba los puntos de vista, frecuentemente equivocados y disparatados, de las grandes escuelas europeas del hormigón armado.

El primer gran éxito de Torroja y sus alumnos fue conseguir que un grupo de técnicos del Consejo Internacional de Edificación y del Comité Europeo del Cemento adoptara los principios básicos de su método de probabilidades para la determinación de los coeficientes de seguridad de las obras. Este método, que ha sido también adoptado por el Instituto Americano del Hormigón, constituye un brillante ejemplo de la armonía reinante entre las directrices de una teoría compleja y las necesidades de simplificación que requiere la práctica. Posteriormente, se ha averiguado que este procedimiento concuerda con el sistema de coeficientes interconexionados que está actualmente en vigor en la U. R. S. S.

A Torroja se le debe, también, la solución del problema que ha originado los debates más enconados en el seno del Comité Europeo: hablamos de la elección de un método simplificado de cálculo en ruptura por flexión. En este asunto, el Profesor Torroja supo realizar una síntesis clara y sencilla de las innumerables proposiciones que se habían presentado; y el control estadístico a que sometió su método del momento tope consiguió la aprobación general.

Además, en el terreno todavía no bien explorado de la ruptura por esfuerzo cortante, una proposición de Torroja, fundada en la interpretación estadística de los datos experimentales, ha permitido al Comité Europeo la adopción de una fórmula provisional, en espera de que las teorías existentes puedan ser perfectamente comprobadas.

Estas son las principales aportaciones de nuestro desaparecido gran amigo a la obra de colaboración europea en el terreno del hormigón armado. Pero, en realidad, se puede perfectamente admitir que su participación se encuentra igualmente en todos los demás problemas objeto de discusión: fisuramiento, pandeo, placas, construcciones hiperestáticas, deformaciones, y tantos otros problemas a los cuales, su mente, profundamente original, aportó progresos notables. Su acción también se ha hecho notar en lo que respecta a la organización de la tarea a realizar por el Comité y al cumplimiento de su programa de actividades: en efecto, no olvidemos que, en 1956, creó las Comisiones especializadas que constituyen actualmente los elementos básicos de la organización.

Estas líneas, en las que he tratado de resaltar la tarea extraordinaria que desempeñaba Torroja en el seno del Comité Europeo del Hormigón, explican que su desaparición haya sido considerada, por todas las Delegaciones europeas, como una pérdida irreparable. Más grande es el dolor de los que tuvimos el privilegio de colaborar más estrechamente con él, para los cuales Eduardo Torroja significa más que un simple maestro: era un amigo incomparable e irreemplazable. 